\title{
Importância da hidrodinâmica na cinética de flotação de partículas grossas
}

\author{
Importance of hydrodynamics in coarse particle flotation kinetics
}

\section{Wendel Johnson Rodrigues}

Doutorando do Departamento de Engenharia de Minas e Petróleo da Escola Politécnica da Universidade de São Paulo E-mail:wjrodrig@usp.br

\section{Laurindo Salles Leal Filho \\ Professor Titular de Tratamento de Minério no Departamento de Engenharia de Minas e Petróleo da Escola Politécnica da Universidade de São Paulo \\ E-mail: lauleal@usp.br}

\section{Resumo}

Os processos básicos que governam a recuperação de partículas em uma célula de flotação compreendem os consecutivos subprocessos de colisão, adesão e estabilidade do agregado partícula/bolha. Entre eles, a colisão é controlada pelo ambiente hidrodinâmico na célula de flotação, enquanto que a adesão é dominada pelo comportamento físico-químico da interface entre partícula e bolha. Por sua vez, a eficiência da estabilidade depende, tanto dos eventos hidrodinâmicos, como dos físico-químicos.

A recuperação de partículas grossas de apatita (densidade 3,08 g/ $\mathrm{cm}^{3}$ ) e esferas de vidro (densidade $2,48 \mathrm{~g} / \mathrm{cm}^{3}$ ) foi medida através de ensaios de microflotação e flotação em escala de bancada, variando-se diferentes parâmetros hidrodinâmicos na célula, como rotação e geometria do impelidor e números adimensionais (Reynolds \& Froude).

Os resultados indicam que velocidades apropriadas do impelidor produziram níveis de turbulência capazes de manter as partículas em completa suspensão, otimizando, assim, a eficiência de colisão entre partículas e bolhas, sem prejudicar a estabilidade dos agregados.

Palavras-chave: Turbulência, suspensão, tamanho de partícula, velocidade, flotação.

\section{Abstract}

The processes that govern the rate of particle recovery in a flotation cell include the following sub-processes: collision, attachment, and stability of the aggregate formed by particles and bubbles. Collision is controlled by bulk hydrodynamics inside the flotation cell, while attachment is largely dominated by variables that belong to the domain of surface chemistry (contact angle, induction time). As for the stability of the particle/bubble aggregate, its efficiency depends on both hydrodynamics plus surface chemistry variables of the system.

The flotation recovery of coarse particles of apatite and glass spheres was measured by micro-flotation and batch flotation tests in which hydrodynamic parameters were evaluated, such as impeller rotational speed, diameter, and geometry, as well as particle size and density.

Results revealed that a proper impeller rotational speed yielded turbulence levels, which enabled to keep particles fully suspended, this way optimizing the collision efficiency between particles and bubbles, without jeopardizing the stability of the particle-bubble aggregates.

Keywords: Flotation, turbulence, suspension, particle size, velocity. 


\section{Introdução}

O tamanho de partícula tem sido foco de décadas de estudos em processamento mineral. Pesquisas em laboratório e plantas industriais, que visaram a correlacionar o diâmetro de partícula com o desempenho da flotação, evidenciaram o decréscimo da recuperação de partículas grosseiras e muito finas. A dificuldade na flotação de partículas finas é atribuída à baixa probabilidade de colisão entre partícula e bolha. Por sua vez, o problema com a flotação das partículas grossas é devido à ruptura do agregado formado entre a partícula e a bolha (Crawford \& Ralston, 1988; Ralston et al., 1999; Rodrigues et al., 2001).

Segundo Derjaguin e Dukhin (1961), os processos que governam a recuperação, ou eficiência de coleta $(E)$, de partículas numa célula de flotaçã̃o compreendem as consecutivas etapas colisão partícula-bolha, adesão e estabilidade do agregado, representadas pelas eficiências $E_{c}, E_{a}$ e $E_{s}$.

$E_{k}=E_{c} \cdot E_{a} \cdot E_{s}$

A eficiência de colisão é dominada pelas condições hidrodinâmicas dentro da célula, como a rotação do impelidor, turbulência e nível de suspensão das partículas, enquanto que a adesão é controlada pelas interações físico-químicas nas interfaces de partícula e bolha, como $\mathrm{pH}$, dosagem de coletor, ângulo de contato e tensão superficial. Por sua vez, a estabilidade do agregado partículabolha depende de ambos os eventos, hidrodinâmicos e físico-químicos (Derjaguin \& Dukhin, 1961; Duan et al., 2003; Grano, 2006).

A operação nas células mecânicas ocorre num ambiente extremamente turbulento. Em escala industrial, o número de Reynolds varia dentro do intervalo de $1 \times 10^{6}$ a $1 \times 10^{7}$. O número de Reynolds do impelidor é definido pela Equação 2. Dessa forma, no interior da célula, as partículas devem ser mantidas em suspensão para propiciar a colisão com as bolhas. Tal evento será causado tanto pela turbulência, originada da rotação do impelidor, como pelo movimento ascen- dente das bolhas dentro da célula. $O$ fenômeno de transporte turbulento caracteriza a macroturbulência. Por outro lado, a dispersão do ar, a colisão partícula-bolha e a estabilidade do agregado são controladas pela microturbulência, cuja intensidade e estrutura dependem somente da taxa de energia dissipada e da viscosidade cinemática da polpa. A taxa de energia dissipada ( $(\varepsilon)$, num tanque agitado e aerado contendo uma massa $\mathrm{M}$ (de água) e tendo uma potência aplicada $\mathrm{P}$, é representada pela Equação 3 (Schubert \& Bischofberger, 1978; Schubert, 1999; Leal Filho et al., 2006).

$\operatorname{Re}=\frac{D^{2} N \rho}{\mu}$

Sendo $D$ o diâmetro do impelidor; $N$, a velocidade rotacional do impelidor, $\rho$, a densidade da polpa e $\mu$, a viscosidade da polpa.

$\varepsilon=\frac{P}{M}$

A suspensão das partículas, no interior de um tanque mecanicamente agitado, ocorre em duas etapas, primeiro, a elevação dos sólidos do fundo do tanque, segundo, a dispersão dos sólidos ao longo da célula (Arbiter, 1999; Schubert, 1999; Van der Westhuizen \& Deglon, 2008).

A velocidade crítica de suspensão ou mínima velocidade de suspensão, $N_{Z}$, define a mínima velocidade do impelidor, que é capaz de manter todos os sólidos em suspensão do fundo do tanque. Zwietering (1958) elaborou o mais extensivo e importante estudo de suspensão de partículas em vasos mecanicamente agitados, propondo "one-second criterion": as partículas não permanecem sedimentadas no fundo do tanque por mais que 1 a 2 segundos. Zwietering desenvolveu uma correlação para determinar a mínima velocidade de suspensão, que considerava os parâmetros hidrodinâmicos do sistema, representada pela Equação 4. No entanto, a correlação de Zwietering não contemplou os sistemas gaseificados (Zwietering, 1958; Duttar \& Pangarkar, 1995; Leal Filho et al., 2006; Van der Westhuizen \& Deglon, 2008).

$N_{z}=\frac{S \cdot v^{0.1} \cdot d_{p}^{0.2} \cdot B^{0.13} g^{0.45}\left(\frac{\rho_{s}-\rho}{\rho}\right)^{0.45}}{D^{0.85}}$

Onde:

$S$ é um parâmetro adimensional relacionado à geometria do impelidor e tanque (forma, tamanho e relações com a geometria do tanque.

$v$ é a viscosidade cinemática da polpa.

$d_{p}$ é o diâmetro da partícula.

$g$ é a aceleração da gravidade.

$\rho_{s}$ é a densidade do sólido.

$\rho$ é a densidade da polpa.

$B$ é a massa de sólidos suspensa pela massa de líquido, vezes 100 .

$D$ é o diâmetro do impelidor.

Posteriormente, a equação da mínima velocidade de suspensão foi desenvolvida para sistemas gaseificados, em virtude do considerável número de processos industriais que usam sistemas trifásicos, caso da flotação (Chapman et al., 1983a; Duttar \& Pangarkar, 1995; Van der Westhuizen \& Deglon, 2007). 
A introdução de gás no sistema proporciona o decréscimo na capacidade de bombeamento do impelidor. Quando isto ocorre, alguns sólidos são depositados no fundo do tanque, aumentando $N_{z}$, que, no sistema trifásico, será representado por $N_{Z G}$. Dessa forma, $\Delta N_{Z}\left(=N_{Z G}-N_{Z}\right)$ é requerido para re-suspender os sólidos (Chapman et al.,1983; Rewatkar \& Joshi, 1991).

Para desenvolvimento das correlações de $N_{Z G}$, dois aspectos devem ser considerados: a vazão de gás (velocidade superficial de gás) e o efeito das outras variáveis, como densidade de sólido e \%sólidos (Chapman et al., 1983, Van der Westhuizen \& Deglon, 2007).

$N_{Z G}$ tende a aumentar linearmente com a adição de gás, conduzindo à Equação 5 (Chapman et al., 1983; Van der Westhuizen \& Deglon, 2007; Rewatkar \& Joshi, 1991).

$N_{Z G}=N_{Z}+a Q_{V G}$

Onde:

$N_{Z G}$ é a velocidade crítica de suspensão para sistemas aerados. $N_{Z}$ é a velocidade crítica de suspensão para sistema sólidolíquido.

" $a$ " é o coeficiente linear, que é função de outras variáveis, sejam geométricas ( $\mathrm{D}, \mathrm{C}$ e $\mathrm{T})$ ou peculiares ao sistema (densidade, percentagem de sólidos, etc).

$Q_{G V}$ é a vazão específica de gás $\left(\min ^{-1}\right)(=$ velocidade superficial do gás/Z).

Z é o nível da polpa (Chapman et al., 1983c; Van der Westhuizen \& Deglon, 2007; Rewatkar \& Joshi, 1991).

Os sucessos dos eventos, colisão, adesão e estabilidade, proporcionarão a coleta da partícula pela bolha, reportandose ao aspecto cinético na flotação. Por outro lado, se um dos eventos não ocorrer, o desempenho do processo será retardado e a partícula não flotará.

Se o ar fornecido é constante, a tendência para alguma alteração na concentração de bolha é pequena. Em tal situação, a equação da velocidade de flotação é expressa pela Equação 6, na qual $k$ é a constante cinética (Finch \& Dobby, 1990; Crawford \& Ralston, 1988).

$-r_{F}=\frac{-d c_{P}}{d t}=k \cdot c_{P}^{n}$

Sendo:

$r_{F}$ é a velocidade da flotação

$C_{p}$ é a concentração de partículas

$t$ é o tempo de flotação

$k$ é a constante cinética de flotação.

$n$ é a ordem cinética de flotação.
Essa pesquisa visa a avaliar a influência dos parâmetros hidrodinâmicos da célula de flotação, como geometria e velocidade rotacional do impelidor, sobre a recuperação e a cinética da flotação de partículas grossas de apatita e esferas de vidro.

\section{Materiais e métodos}

Nesse trabalho, foram utilizados cristais de apatita (densidade $\left.=3,08 \mathrm{~g} / \mathrm{cm}^{3}\right)$, secos e moídos até $100 \%$ passante em $0,295 \mathrm{~mm}$. Posteriormente, eles foram classificados na fração $-0,295+0,208 \mathrm{~mm}$. Também se utilizaram esferas de vidro (densidade $=2,48 \mathrm{~g} / \mathrm{cm}^{3}$ ), que, novamente, foram classificadas na fração $-0,295+0,208 \mathrm{~mm}$. Por conseguinte, o diâmetro médio das partículas de apatita e esfera de vidro foi da ordem de $0,248 \mathrm{~mm}$, calculado da média aritmética das malhas utilizadas no peneiramento.

Oleato de sódio, grau analítico, foi aplicado como coletor para apatita, enquanto que, nas esferas de vidro, utilizou-se acetato de eteramina, ambos reagentes com concentração de $1 \%$. Hidróxido de sódio e ácido clorídrico, também grau analítico e concentração de $10 \%$, foram os reguladores de $\mathrm{pH}$.

A tensão superficial foi determinada pelo método da placa de Wilhelmy, devido a sua importância para a caracterização hidrodinâmica do sistema. Por sua vez, as medidas de ângulo de contato $(\theta)$ das esferas de vidro foram realizadas através da técnica de taxa de penetração de líquido, o método de Washburn, que consiste na determinação da altura de penetração do líquido em capilares de um leito compacto de partículas contidas num tubo de vidro ("garrafa") em função do tempo. O fundo do tubo é lacrado com uma placa porosa de 1 a $2 \mathrm{~mm}$ de espessura para reter as partículas (Subrahmanyam et al., 1999).

Os ensaios de flotação foram executados numa célula de microflotação (diâmetro $=32,2 \mathrm{~mm}$; altura $=94,2 \mathrm{~mm}$ ), cuja forma e geometria se assemelham ao tradicional tubo de Hallimond modificado. Na flotação das esferas de vidro, adicionaram-se $60 \mathrm{~mL}$ de solução aquosa de eteramina com concentração $75 \mathrm{mg} / \mathrm{L}$ e pH=10, enquanto que, para apatitas, utilizaram-se $60 \mathrm{~mL}$ da solução aquosa de oleato (1\%) na concentração de $100 \mathrm{mg} / \mathrm{L}$ e pH 10,5. Injetou-se gás nitrogênio no sistema, numa vazão de $9,0.10^{-4} \mathrm{dm}^{3} / \mathrm{s}$, com "hold up" de gás da ordem de $3 \%$ (observação visual) e ele foi flotado durante 60 segundos.

A suspensão da polpa foi realizada por um sistema de agitação mecânica com controle da velocidade rotacional e impelidor cilindróide. Tal rotação variou dentro de um amplo intervalo: 0,07 a 49,33 s-1. A velocidade crítica do impelidor para completa suspensão $\left(N_{Z}\right)$ foi determinada pela observação visual. $N_{Z}$ possibilitou estimar o parâmetro geométrico $(S)$, que caracteriza o impelidor cilindróide usado nos ensaios de flotação. Os valores calculados de $S_{Z}$ e dimensões dos impelidores cilindróides são apresentados na Figura 1. 
Os ensaios cinéticos da microflotação de esferas de vidro (diâmetro médio de $0,248 \mathrm{~mm}$ ) foram realizados em intervalos de 15 segundos até completarem 1 minuto. Além disto, utilizando fosfato de Tapira-MG, oriundo da Fosfértil S.A., executaram-se ensaios em célula Denver, escala de laboratório, (diâmetro do impelidor $=0,07 \mathrm{~m}$ e rotação do impelidor=18,3 rps). A composição mineralógica do minério de fosfato foi constituída, em massa por apatita, $18 \%$; carbonatos, 7\%; micas, $13 \%$; quartzo, $20 \%$; diopsídio, $12 \%$ e óxidos de Fe e Ti com 13\%.

Os ensaios de flotação do minério de fosfato (granulometria entre 20 e $296 \mu \mathrm{m}$ ) apresentaram as seguintes condições: porcentagem de sólidos (v/v) da ordem de $12 \%$; dosagem de amido de $500 \mathrm{~g} / \mathrm{t}$; dosagem de coletor, $350 \mathrm{~g} / \mathrm{t}$, sendo esse coletor composto de $80 \%$ de óleo de arroz e $20 \%$ de KE- $883^{\circledR}$ (fabricado pela Cognis); $\mathrm{pH}$ de flotação foi de 9,3; a espuma foi coletada de modo acumulativo nos intervalos de tempo $(\Delta \mathrm{t})$ de $5,15,35$ e $80 \mathrm{seg}$. Os produtos da flotação foram secados, pesados e enviados para análise química e a recuperação foi calculada em função da quantidade de $\mathrm{P}_{2} \mathrm{O}_{5}$ contido no flotado e na alimentação do ensaio.

\section{Resultados e discussões}

Uma vez que as partículas estão completamente suspensas durante a flotação, a velocidade rotacional do impelidor é suficiente para promover o encontro entre partícula e bolha. Dessa forma, a razão $N / N_{Z}$ se torna uma importante ferramenta para avaliar a capacidade do ambiente hidrodinâmico na célula proporcionar uma melhor probabilidade de colisão entre partícula-bolha. Os efeitos da suspensão da partícula, da velocidade rotacional do impelidor e das características geométricas da célula na recuperação das esferas de vidro (diâmetro $\cong 0,248 \mathrm{~mm}$ ) nos ensaios de microflotação são apresentados na Figura 2. Nesses ensaios, ressaltam-se, ainda, o diâmetro de bolha $\cong 0,374 \mathrm{~mm}$, ângulo de contato $(\theta)=890$, a tensão superficial $\cong 32 \mathrm{mN} / \mathrm{m}$ (eteramina como coletor) e o gás hold-up de $3 \%$.
Nesses ensaios, não foi possível observar o efeito da injeção de gás sobre a mínima velocidade de suspensão, devido ao baixo hold-up.

Porém evidenciou-se que a velocidade rotacional do impelidor próxima à mínima velocidade de suspensão, $N / N_{Z} \cong 1$, alcançou a máxima recuperação das esferas de vidro (>90\%). Além

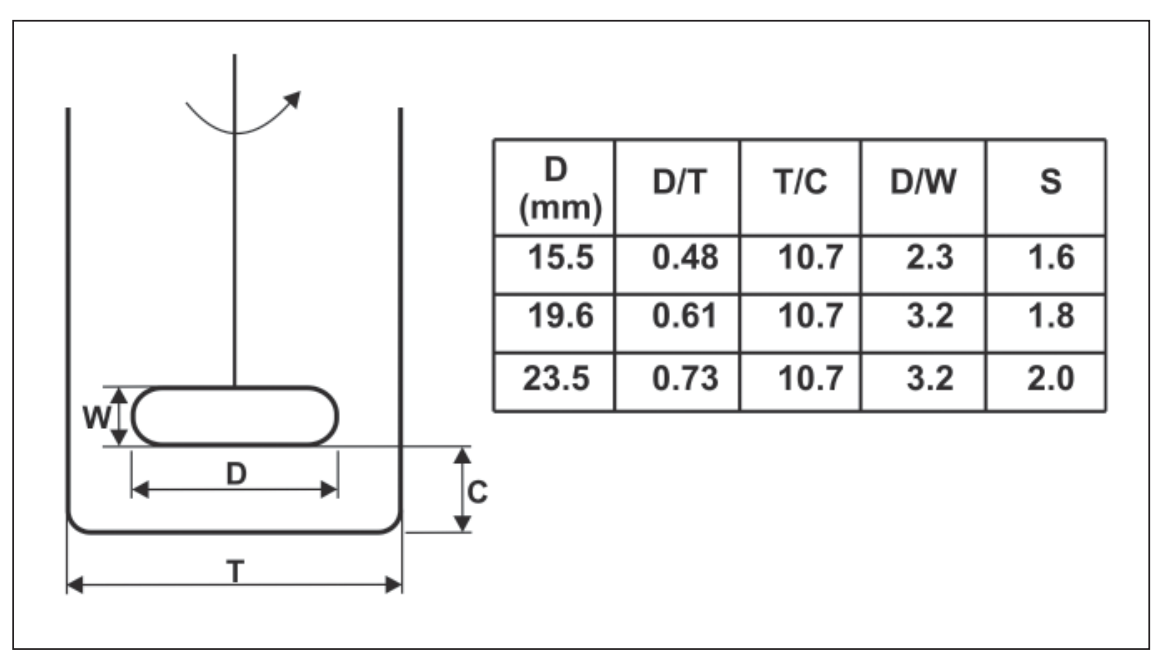

Figura 1 - Características geométricas dos impelidores cilindróides utilizados nos ensaios de microflotação.

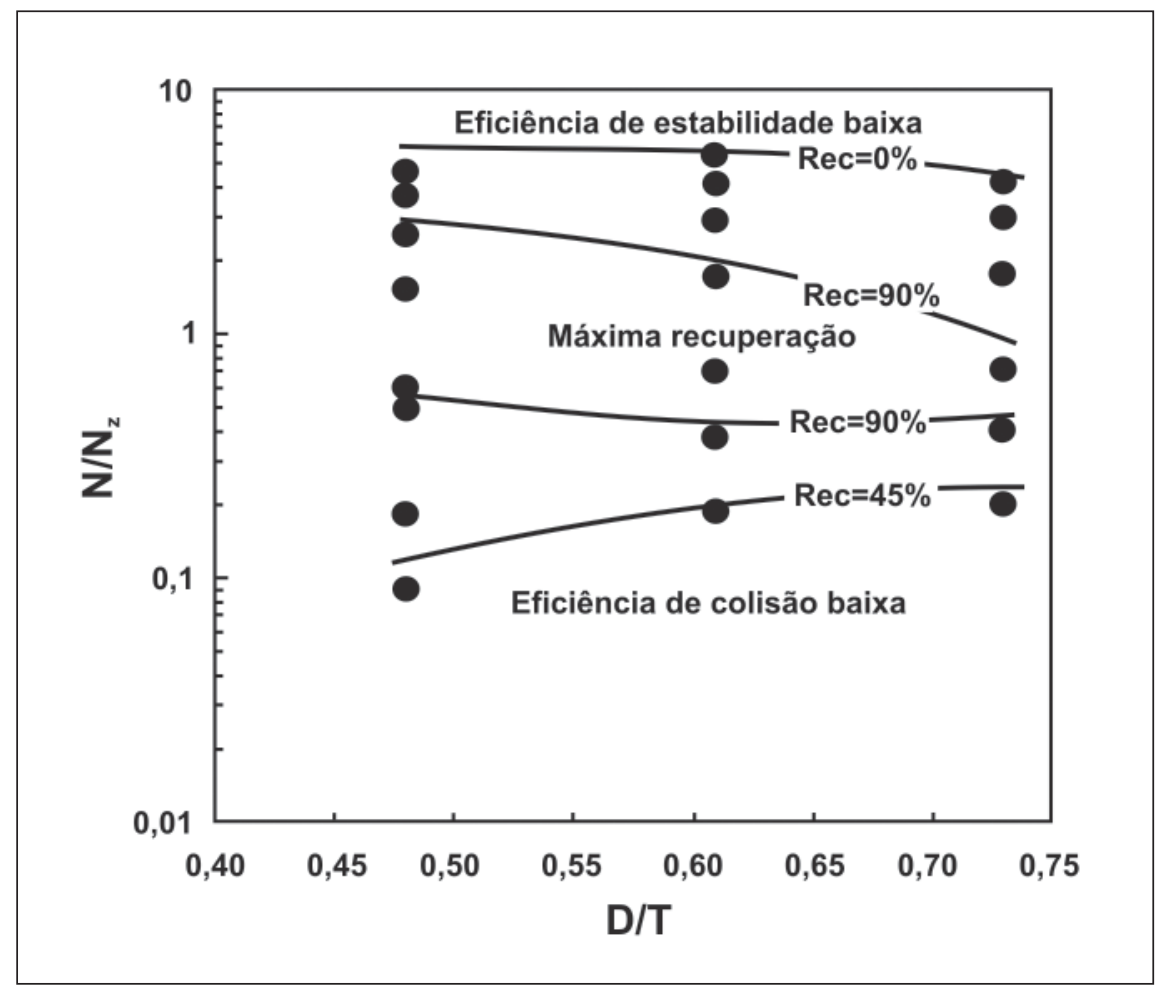

Figura 2 - Influência das características geométricas da célula (D/T) e capacidade do impelidor manter as partículas em suspensão $\left(N / N_{z}\right)$ na recuperação das esferas de vidro. 
As recuperações para a apatita e para as esferas de vidro (diâmetro $\cong 0,248 \mathrm{~mm}$ ) em função do número de Reynolds do impelidor, são comparadas na Figura 3. Observou-se, nessa figura, que a máxima recuperação de apatita se limitou ao intervalo $3000<\operatorname{Re}<5000$, enquanto que as esferas de vidro atingiram seus melhores resultados com Reynolds entre 1500 e 7000. As diferenças entre os intervalos indicaram que as partículas de apatita apresentam maior sensibilidade à turbulência que as esferas de vidro, em virtude de sua maior densidade, assim como as esferas de vidro necessitam de menor velocidade rotacional do impelidor para completa suspensão em condições menos turbulentas, $\operatorname{Re}<2000$, o que é evidenciado por sua melhor recuperação nestas condições.

A influência da taxa de energia dissipada na flotação de partículas grossas de apatita e esferas de vidro é apresentada na Figura 4, onde se identifica que a máxima recuperação de apatita é atingida numa taxa de energia dissipada entre 0,055 e $0,18 \mathrm{~W} / \mathrm{kg}$, enquanto que, no intervalo de 0,0062 a $0,4 \mathrm{~W} / \mathrm{kg}$, as esferas de vidro apresentam sua máxima recuperação. Essas altas recuperações evidenciam que a flotabilidade das partículas grossas demanda uma determinada turbulência na célula para maior eficiência da colisão partícula-bolha e menor taxa de ruptura do agregado. Assim, a taxa de energia dissipada pelo impelidor deve ser suficiente para manter as partículas em completa suspensão, sem prejudicar os agregados de partícula-bolha.

Uma vez que as condições hidrodinâmicas, durante a flotação, interferem nas probabilidades de colisão e preservação do agregado, a cinética da flotação também dependerá dos parâmetros hidrodinâmicos da célula. Sob condições muito turbulentas, que caracterizam a célula Denver de laboratório, Re da ordem de $1,18.10^{5}$, o comportamento cinético do minério de fosfato da mina de Tapira foi avaliado e seus resultados são apresentados nas Figuras 5 e 6.

Através das Figuras 5 e 6, observa-se que as partículas grosseiras tendem a apresentar cinética mais lenta no processo, como pode ser evidenciado pelo aumento de sua ordem. Por sua vez, as partículas de diâmetros inferiores possuem melhor desempenho cinético de flotação, o que é ratificado em função de suas constantes cinéticas maiores.

\section{Conclusão}

Os parâmetros hidrodinâmicos, como velocidade rotacional do impelidor, turbulência e densidade de sólidos, apresentam um papel fundamental na flotação, principalmente no caso das partículas grossas. Sob esse aspecto, os parâmetros adimensionais, como número de Reynolds, a razão entre a velocidade rotacional do impelidor $(N)$ e a mínima velocidade de suspensão $\left(N_{Z}\right)$ e a taxa de energia dissipada, podem ser utilizados para caracterização do ambiente hidrodinâmico da célula.

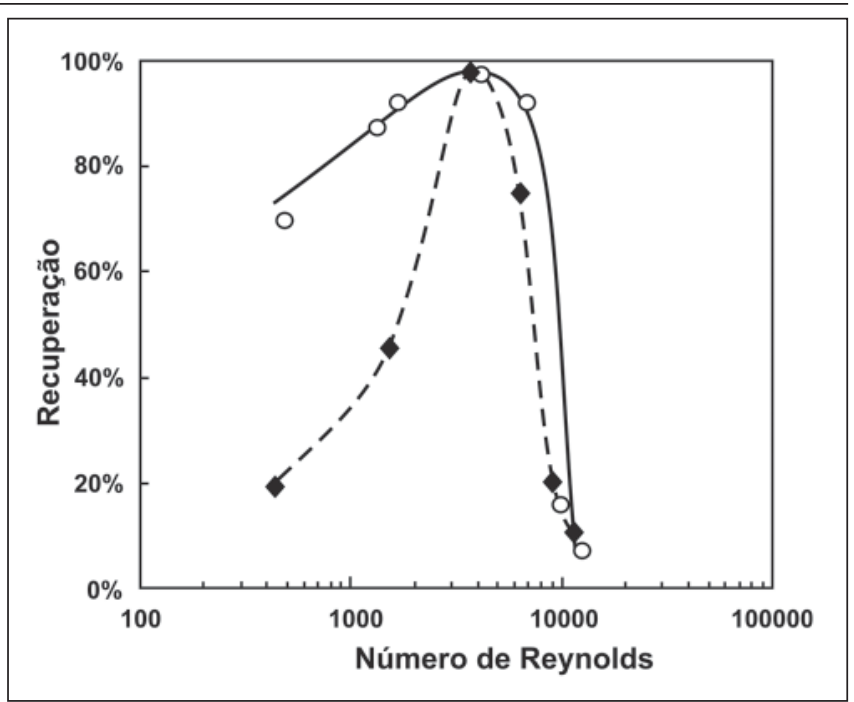

Figura 3 - Reynolds do impelidor versus recuperação de apatita (•) e esferas de vidro (o).

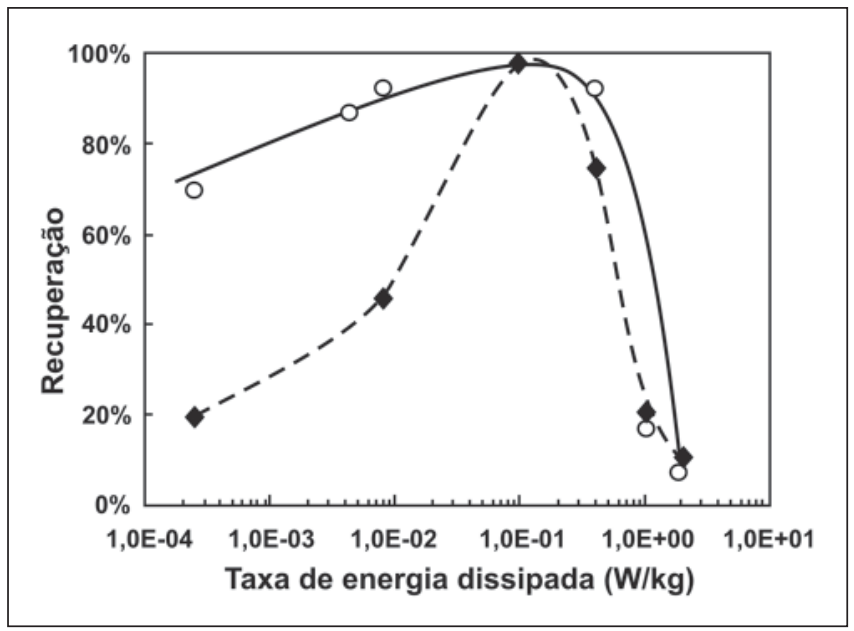

Figura 4 - Taxa de energia dissipada versus recuperação de apatita $(\diamond)$ e esferas de vidro (o).

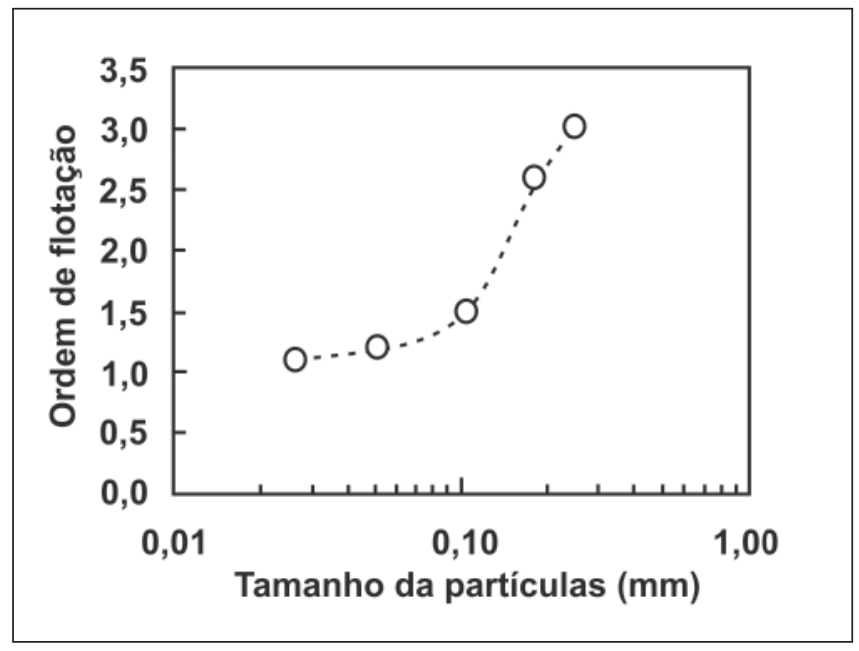

Figura 5 - Ordem da flotação versus tamanho da partícula de apatita em célula Denver de laboratório. 
As máximas recuperações, tanto das esferas de vidro, como das partículas de apatita, ambas de diâmetro $=0,248 \mathrm{~mm}$ foram obtidas quando a razão $N / N_{7}$ estava próxima da unidade. Nessa condição, o ambiente no interior da célula foi capaz de aumentar a freqüência de colisão entre partícula e bolha e permitir a adesão entre elas, uma vez que a termodinâmica estava favorável - ângulo de contato $90^{\circ}$, alcançando, dessa forma, os melhores índices de flotabilidade. Todavia, essa mesma turbulência, elevada a um determinado nível, $N / N_{Z}>>1$, prejudicará a estabilidade dos agregados partículabolha, decrescendo, assim, a eficiência de coleta na flotação.

A lenta cinética de partículas grossas, evidenciada pelo aumento da ordem de flotação, corrobora que tais faixas granulométricas são prejudicadas em função do aumento de turbulência no interior da célula.

\section{Referências bibliográficas}

ARBITER, N. Development and scale - up of large flotation cells. In: Advances in Flotation Technology. PAREKH, B.K. MILLER, J. D. (ed.). Littleton, CO: SME, 1999. p. 345-53.

CHAPMAN, C. M., NIENOW, A. W. et al. Particle-gas-liquid mixing in stirred vessels. Part III: Three phase mixing. Chemical Engineering Research \& Design, v. 61, p. 167-81, 1983.

CRAWFORD, R., RALSTON, J. The influence of particle size and contact angle in mineral flotation. International Journal of Mineral Processing, v. 23, n. 1-2, p. 1-24, 1988.

DERJAGUIN, B. V., DUKHIN, S. S. Theory of flotation of small and medium size particles. Transactions of the American Institute of Mining and Metallurgical Engineers, v. 70, p. 221-46, 1961.

DUAN, J., FORNASIERO, D., RALSTON, J. Calculation of the flotation rate constant of chalcopyrite particles in an ore. International Journal of Mineral Processing, v.72, n.1-4, p.227-237, 2003.

DUTTA, N. N., PANGARKAR, V. G. Critical impeller speed for solid suspension in multi - impeller three phase agitated contactors. The Canadian Journal of Chemical Engineering, v. 73, n. 3, p. 273-283, 1995.

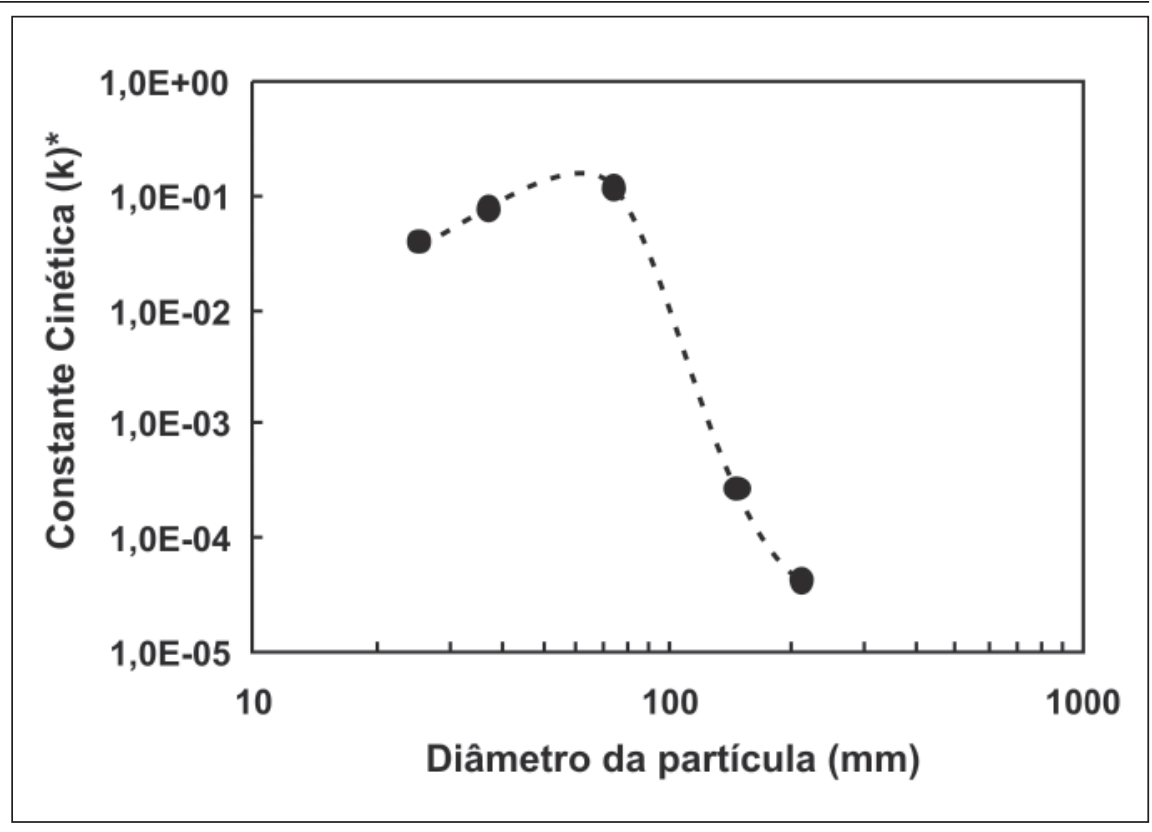

Figura 6 - Influência do diâmetro da partícula de apatita na constante cinética de flotação em célula Denver de laboratório.

FINCH, J.A., DOBBY, G.S. Column flotation. Oxford: Pergamon Press, 1990. 180p.

GRANO, S. Effect of impeller rotational speed on the size dependent flotation rate of galena in full scale plant cells. Minerals Engineering, v. 19, n. 13, p. 1307-1318. 2006.

LEAL FILHO, L. S., RODRIGUES, W. J., LIMA, O. A., BARROS, L. A. F. The role of hydrodynamics in coarse apatite flotation. Beneficiation of Phosphates: Technology and Sustainability. Littleton-Colorado: Society of Mining, Metallurgy and Exploration, Inc (SME), 2006. p. 25-36.

SCHUBERT, H., BISCHOFBERGER, C. On the hydrodynamics of flotation machines. International Journal of Mineral Processing, v. 5, n. 2, p. 131-142, 1978.

SCHUBERT, H. On the turbulence - controlled microprocesses in flotation machines. International Journal of Mineral Processing, v. 56, n. 1-4, p. 257-276, 1999.

SUBRAHMANYAM, T. M., MONTE, M. B. M., MIDDEA, A., VALDIVIEZO, E., LINS, F. F. Contact angles of quartz by capillary penetration of liquids and captive bubble techniques. Minerals Engineering, v. 12, n. 11, p. 1347-1357, 1999.

RALSTON, J., FORNASIERO, D., HAYES, R. Bubble-particle attachment and detachment in flotation. International Journal of Mineral Processing, v.56, n.1-4, p. 133-164, 1999.

REWATKAR, V. B., JOSHI, J. B. Critical impeller speed for solid suspension in mechanically agitated three - phase reactors 2: mathematical model. Industrial \& engineering chemistry research, v. 30, n. 8, p. 1784-91, 1991.

RODRIGUES, W. J., LEAL FILHO, L. S., MASINI, E. A. Dimensionless hydrodynamic parameters and their influence on flotation behavior of coarse glass spheres. Minerals Engineering, v. 14, n. 9, p. 1047-1054, 2001.

VAN DER WESTHUIZEN, A. P., DEGLON, D. A. Evaluation of solids suspension in a pilot-scale mechanical flotation cell: The critical impeller speed. Minerals Engineering, v. 20, p. 233-40, 2007.

VAN DER WESTHUIZEN, A.P., DEGLON, D.A. Solids suspension in a pilot-scale mechanical flotation cell: A critical impeller speed correlation. Minerals Engineering, v. 21, n. 8, p. 621-629, 2008.

ZWIETERING, T. N. Suspending of solid particles in liquid by agitators. Chemical Engineering Science, v. 8, n. 3-4, p. 244-253, 1958.

Artigo recebido em 06/07/2010 e aprovado em 17/08/2010. 